\title{
Reflexões contemporâneas sobre a exploração sexual comercial de crianças e adolescentes no mercado do turismo no Peru*
}

\author{
Franciele Letícia Kühla - André Viana Custódiob,
}

Resumo: este trabalho busca verificar se há relação entre as normas e as políticas públicas com as causas da exploração sexual comercial infantil no turismo no Peru. Para alcançar esse objetivo, estudou-se a proteção jurídica e as políticas públicas nacionais e internacionais que regulamentam o trabalho infantil no Peru, bem como analisou-se os resultados obtidos pela End Child Prostitution, Child Pornography and Trafficking of Children for Sexual Purposes (ECPAT), no "Global study on sexual exploitation of children in travel and tourism: regional report Latin America", de 2016, que trouxe a pobreza, a baixa escolaridade e a ausência de programas específicos como principais fatores de exploração sexual comercial infantil. Apesar dos avanços legislativos e dos esforços de políticas públicas que buscam erradicar o trabalho infantil, as causas da exploração sexual comercial infantil ainda existem. O método de abordagem é dedutivo e o método de procedimento monográfico é com base em pesquisa bibliográfica e documental.

Palavras-chave: exploração sexual comercial; Peru; trabalho infantil

Recibido: 05 de junio de 2018 Aceptado: 22 de abril de 2020

Disponible en línea: día, mes y año.

Cómo citar: Kühl, F. L., \& Custódio, A. V. (2020). Reflexões contemporâneas sobre a exploração sexual comercial de crianças e adolescentes no mercado do turismo no Peru. Prolegómenos, 23(46). 105120. DOI:https://doi.org/10.18359/prole.3505

* Artigo vinculado ao projeto institucional de pesquisa em políticas públicas de prevenção e erradicação do trabalho infantil do Grupo de Pesquisa Políticas Públicas de Inclusão Social, financiado pela Universidade de Santa Cruz do Sul (UnISC).

a Mestre no Programa de Pós-Graduação em Direito na Universidade de Santa Cruz do Sul, na linha de políticas públicas para a inclusão social. Membro do Grupo de Estudos em Direitos Humanos de Crianças, Adolescentes e Jovens. Professora no curso de Direito da Faculdade Dom Alberto. Professora nos Cursos Preparatórios do CEIsc, Santa Cruz do Sul, Brasil. E-mail: kuhlfranciele@gmail.com

b Pós-doutor em Direito pela Universidade de Sevilha (Espanha), doutor e mestre em Direito pela Universidade Federal de Santa Catarina, professor permanente do Programa de Pós-Graduação em Direito Mestrado e Doutorado da Universidade de Santa Cruz do Sul, líder do Grupo de Pesquisa Políticas Públicas de Inclusão Social e coordenador do Grupo de Estudos em Direitos Humanos de Adolescentes da UNISC, Santa Cruz do Sul, Brasil.E-mail: andreviana.sc@gmail.com 


\title{
Contemporary reflections on commercial sexual exploitation of children and adolescents in the tourism market in Peru
}

\begin{abstract}
This work seeks to prove the relationship between public policies and norms and the causes of commercial sexual exploitation of children in tourism in Peru. To achieve this purpose, legal protection and national and international public policies regulating child labor in the country were studied, as well as the results obtained by End Child Prostitution, Child Pornography and Trafficking of Children for Sexual Purposes, in the "Global study on sexual exploitation of children in travel and tourism: regional report Latin America", 2016, which brought poverty, low educational level and the absence of specific programs as the main factors of commercial sexual exploitation of children. Despite regulatory advances and public policy efforts to eradicate child labor, the causes of commercial child sexual exploitation still persist. The approach method is deductive and the monographic procedure method is bibliographic and documentary research.
\end{abstract}

Keywords: commercial sexual exploitation; Peru; child labor

\section{Reflexiones contemporáneas sobre la explotación sexual comercial en niños y adolescentes en el mercado del turismo en Perú}

Resumen: El trabajo busca evidenciar la relación entre las normas y las políticas públicas con las causas de la explotación sexual comercial infantil en el turismo en Perú. Para lograr el propósito se estudió la protección jurídica y las políticas públicas nacionales e internacionales que normatizan el trabajo infantil en el país, así como se analizaron los resultados obtenidos por la End Child Prostitution, Child Pornography and Trafficking of Children for Sexual Purposes, en el "Global study on sexual exploitation of children in travel and tourism: regional report Latin America", de 2016, que trajo la pobreza, el bajo nivel educativo y la ausencia de programas específicos como principales factores de la explotación sexual comercial infantil. A pesar de los avances normativos y los esfuerzos de políticas públicas que buscan erradicar el trabajo infantil, las causas de la explotación sexual comercial infantil aun persisten. El método de enfoque es deductivo y el método de procedimiento monográfico es la investigación bibliográfica y documental.

Palabras clave: explotación sexual comercial; Perú; trabajo infantil 


\section{Introdução}

Há diversas normas sociais, práticas tradicionais, costumes e ações governamentais e não governamentais, além da proteção jurídica nacional e internacional, que visam a garantir a proteção integral da criança e do adolescente. Contudo, em razão da globalização, da internet, da tecnologia móvel, dos novos serviços de viagens e turismo e do grande investimento dos Estados nas atrações turísticas, a circulação de pessoas por todos os países aumentou consideravelmente e, consequentemente, a violação de direitos de crianças e adolescentes expostos à capitalização e à comercialização de seus corpos para suprir a falta de condições mínimas de vida.

Apesar dos avanços na proteção jurídica em âmbito nacional e internacional quanto aos direitos das crianças e dos adolescentes, com base na construção sistemática de garantias e políticas públicas no enfrentamento de todas as formas de exploração e violação de direitos de crianças e adolescentes, ainda são necessários muitos avanços para evitar a exploração sexual comercial infantil no turismo.

No presente artigo, buscou-se verificar se há relação entre as normas e as políticas públicas com as causas da exploração sexual comercial infantil no turismo no Peru. Para alcançar tal objetivo, no primeiro e no segundo capítulo são estudadas as proteções jurídicas e as políticas públicas nacionais e internacionais que regulamentam e asseguram os direitos de crianças e adolescentes no trabalho infantil no Peru, e o que esse país tem feito para buscar a erradicação da exploração sexual comercial de crianças e adolescentes.

No terceiro capítulo, analisou-se o relatório "Global study on sexual exploitation of children in travel and tourism: regional report Latin America", de 2016, resultado do trabalho da End Child Prostitution, Child Pornography and Trafficking of Children for Sexual Purposes (ЕСРAT), que trata sobre o aumento crescente da exploração sexual comercial infantil nos países da América Latina. A ECPAT iniciou suas campanhas em 1990 para acabar com a exploração sexual comercial infantil no turismo asiático; hoje é a única rede internacional de uma organização não governamental exclusivamente dedicada à luta contra exploração sexual comercial de crianças, apoiando 97 organizações parceiras da sociedade civil espalhadas por 88 países.

O quarto capítulo reflete sobre o aumento descontrolado dos interesses econômicos, tanto do Estado como das instituições privadas e da própria sociedade, dominados pelo hiperconsumismo globalizado, somado às desigualdades sociais, que vem gerando graves violações de direitos humanos.

O estudo especifica o trabalho infantil na modalidade de exploração sexual comercial no turismo, com foco no Peru, mas pode ser encontrado em diversos locais de turismo intenso. Ademais, o baixo índice de desenvolvimento, uma realidade de extrema pobreza e a baixa escolaridade, características da região estudada, não permitem uma conscientização sobre a prejudicialidade dessa espécie de trabalho. O método de abordagem é dedutivo e o método de procedimento monográfico é com base em pesquisa bibliográfica e documental.

\section{Avanços jurídicos internacionais quanto à proteção de crianças e adolescentes e à proteção internacional ao trabalho infantil}

A violência contra os direitos fundamentais de crianças e adolescentes é um fenômeno complexo presente na sociedade contemporânea e que deve ser enfrentado pela sociedade, em todo o mundo. Um dos principais tipos de violência aos direitos fundamentais é o trabalho infantil.

Entre as principais convenções internacionais que tratam sobre a proteção dos direitos humanos e dos direitos fundamentais de crianças e adolescentes está a Convenção sobre os Direitos da Criança, da Organização das Nações Unidas (ONU), de 1989, ratificada por 196 países, incluindo o Peru.

A Convenção sobre os Direitos da Criança foi um marco internacional na busca pela efetivação de direitos, com o objetivo de possibilitar a proteção absoluta a fim de garantir o desenvolvimento integral dessas pessoas que se encontram 
em situação peculiar de desenvolvimento moral, físico, psicológico, social, intelectual e cultural (Custódio e Veronese, 2013). Está determinado que toda pessoa, sem distinção de raça, cor, sexo, idioma, crença, posição política, origem nacional ou social e posição econômica, possui seus direitos assegurados na Convenção (Brasil, 1990).

No artigo 19, a Convenção trata sobre a responsabilidade do Estado em adotar medidas legislativas, administrativas, sociais e educacionais apropriadas para proteger as crianças de todas as formas de violência, enquanto a criança ou o adolescente estiver sob a custódia dos pais, do representante legal ou de qualquer pessoa responsável pela sua proteção. Essas medidas devem incluir procedimentos eficazes para a elaboração de programas sociais capazes de proporcionar uma assistência adequada à criança e às pessoas encarregadas de seu cuidado, bem como outras formas de prevenção para identificação, notificação, investigação, tratamento, acompanhamento posterior e intervenção judiciária de casos de maus-tratos à criança (Brasil, 1990).

No artigo 32 da Convenção foi reconhecido o direito da criança de estar protegida contra a exploração econômica e contra o desempenho de qualquer trabalho que possa ser perigoso, que interfira em sua educação ou que seja nocivo para sua saúde ou para seu desenvolvimento físico, mental, espiritual, moral ou social. Além disso, define que os Estados deverão estabelecer uma idade ou idades mínimas para admissão em emprego, regulamentação apropriada relativa a jornadas e condições de trabalho e penalidades ou sanções apropriadas para assegurar o cumprimento efetivo do artigo 32 (Brasil, 1990).

Outra importante determinação da Convenção na proteção à exploração econômica é a imposição aos Estados-membros de comprometer-se a proteger crianças de todas as formas de exploração e abuso sexual. Nesse sentido, todos os Estados devem tomar medidas de caráter nacional e internacional que sejam necessárias para impedir o incentivo ou a coação, a fim de evitar que uma criança se dedique a qualquer atividade sexual, segundo o artigo 34 da Convenção sobre os Direitos da Criança (Brasil, 1990)ํ․
O Protocolo Facultativo da Convenção sobre os Direitos da Criança relativo à exploração sexual comercial infantil e à utilização de crianças para pornografia, também ratificado pelo Peru em outubro de 2001, preocupa-se com a prática disseminada e continuada do turismo sexual. Em razão disso, amplia as medidas a serem adotadas pelos Estados-membros para garantir a proteção da criança na exploração econômica.

Este Protocolo es complementario a la Convención sobre los Derechos del Niño; y establece que los Estados Partes, convienen que prohibirán la venta de niños, la prostitución infantil y la pornografía infantil, de conformidad con lo que se dispone en este documento. Asimismo, amplía las medidas que deben adoptar los Estados Partes, para garantizar la protección de los menores contra la venta de niños, la prostitución infantil y la utilización de niños en la pornografía; facilitando así, la aplicación de las disposiciones 1, 11, 21 y del 32 al 36 de la Convención sobre los Derechos del Niño (Fundamentals e Ministerio de Trabajo y Promoción del Empleo del Perú, 2016, p. 24).

A proteção internacional contra a exploração do trabalho infantil tem proporcionado importantes instrumentos para os países, garantindo estratégias de efetivação de direitos fundamentais. Essa proteção, no que se refere ao trabalho infantil especificamente, é normatizada pela Organização Internacional do Trabalho (OIT), "a qual tem possibilitado as conquistas mais importantes na proteção de crianças e adolescentes contra a exploração no trabalho" (Custódio e Veronese, 2007, p. 181).

A OIT é o organismo responsável pela emissão de normas referentes ao trabalho, determinando garantias mínimas aos trabalhadores, além de ser

1 “Os Estados-Partes se comprometem a proteger a criança contra todas as formas de exploração e abuso sexual. Nesse sentido, os Estados-Partes tomarão, em especial, todas as medidas de caráter nacional, bilateral e multilateral que sejam necessárias para impedir: a) o incentivo ou a coação para que uma criança se dedique a qualquer atividade sexual ilegal; b) a exploração da criança na prostituição ou outras práticas sexuais ilegais; c) a exploração da criança em espetáculos ou materiais pornográficos” (Brasil, 1990). 
responsável por controlar e fiscalizar a execução e o alcance das metas ratificadas pelos países signatários. "Sua composição envolve representantes dos trabalhadores, dos empregadores e dos governos da grande maioria dos países" (Custódio e Veronese, 2007, p. 181).

Originalmente criada em 1919, como parte do Tratado de Versalhes, na primeira Conferência Internacional do Trabalho realizada no mesmo ano, a OIT adotou seis convenções principais, estabelecendo importantes garantias aos trabalhadores, como limitação da jornada de trabalho; proteção ao trabalho infantil, às mulheres e à maternidade; e, principalmente, compreensão para a necessidade de erradicação do trabalho infantil e proteção dos direitos do adolescente trabalhador (Custódio e Veronese, 2007). Combater o trabalho infantil não é uma tarefa fácil. Segundo Javier Neves Mujica (2013, p. 2),

Hay que advertir que el Derecho es siempre un ideal, que está - especialmente en países de extendida informalidad, como el nuestro - a considerable distancia de la realidad. En materia de trabajo infantil, la brecha entre aquel y esta es enorme. En todo caso, su principal valor reside en que precisa un objetivo que debería orientar las políticas públicas en dicha dirección.

Desde sua primeira conferência geral, a OIT mostrou-se preocupada com o trabalho infantil. A Convenção 138 da OIT, de 1973, por exemplo, estabeleceu a idade mínima para o trabalho infantil e teve como objeto o controle eficaz da exploração do trabalho infantil, considerando a necessidade de adotar novos instrumentos que orientassem medidas imediatas e eficazes para alcançar a proibição e a eliminação das piores formas de trabalho infantil. Posteriormente, veio a Convenção 182, complementando a Convenção 138, que tratou das piores formas de trabalho infantil, e a Recomendação 190, com mecanismos e orientações para o aperfeiçoamento das políticas públicas. Todas as convenções foram ratificadas pelo Peru.

La Recomendación 190, complementa al Convenio 182 y brinda especificaciones para operativizar disposiciones del mismo, en materia de programas de acción, de trabajo peligroso, de seguimento y sanción de quienes cometan delitos en este ámbito; y de generación de información estadística. En este Convenio se reconoce que el trabajo infantil se vincula a la pobreza y que la solución a largo plazo radica en el crecimiento económico con progreso social y mitigación de la pobreza; pero que la eliminación efectiva de las peores formas de trabajo infantil requiere de una acción inmediata, que considere la importancia de la educación básica gratuita, atender la rehabilitación de los niños y las necesidades de sus familias (Fundamentals e Ministerio del Trabajo y Promoción del Empleo del Perú, 2016, p. 23).

Entre as principais atividades consideradas como as piores formas de trabalho infantil estão todas as formas de escravidão ou práticas análogas (como a venda e o tráfico de crianças, servidão por dívida, condição de servo, trabalho forçado ou obrigatório, recrutamento em conflitos armados), a exploração sexual (recrutamento ou oferta de crianças para a prostituição, produção ou atuação pornográfica), as atividades ilícitas (como o tráfico de entorpecentes), o trabalho que por sua natureza cause danos à saúde, à segurança e à moralidade das crianças e dos adolescentes (Organização Internacional do Trabalho, 1999).

A Convenção 182 destaca a procura e a oferta de crianças para fins de prostituição, a produção de material pornográfico ou espetáculos pornográficos como uma das piores formas de trabalho, ainda que muitas vezes seja difícil de caracterizar tal exploração como trabalho, "nada mais são do que trabalhos não apenas prejudiciais ao desenvolvimento, como também, à moralidade" (Custódio e Veronese, 2007, p. 217). Nessa senda, a Recomendação 190 da OIT traz atenção especial aos trabalhos que expõem as crianças aos abusos físicos, psicológicos e sexuais.

A intenção da Convenção 182 é garantir o pleno desenvolvimento de crianças e adolescentes, mediante políticas públicas, ações governamentais e conscientização dos Estados-membros, com ênfase nas políticas educacionais, socioassistenciais e de erradicação da pobreza.

Importante estabelecer que, embora os documentos internacionais utilizem o termo "prostituição", esse conceito não é o mais adequado, pois a prostituição é uma profissão. Contudo, quando exercida por crianças e adolescentes, caracteriza-se conceitualmente como exploração sexual comercial, que é uma das piores formas de trabalho infantil. 
As organizações internacionais, que são compostas dos mais diversos países, incentivam a criação de políticas públicas para o enfrentamento da exploração sexual comercial, bem como de todas as formas de trabalho infantil em geral. Os Estados-membros que ratificam as convenções dessas organizações internacionais assumem compromissos de desenvolver políticas públicas com a finalidade de erradicação do trabalho infantil, assim como ocorre no Peru, que é um exemplo de estratégias e de preocupação para erradicação do trabalho infantil.

Outras iniciativas no combate à exploração sexual comercial de crianças e adolescentes no turismo buscam a erradicação dessa forma de violência, como o The Code of Conduct for the Protection of Children from Sexual Exploitation in Travel and Tourism (The Code), representado no Peru pelo Capital Humano y Social Alternativo. O The Code é uma iniciativa multissetorial que tem a missão de fornecer conscientização, ferramentas e apoio à indústria de turismo, a fim de prevenir a exploração sexual de crianças e adolescentes, denominada pelo The Code como explotación sexual de niñas, niños y adolescentes (ESNNA). Quando uma empresa se torna membro do The Code, poderá fazer uso de sua logo na página de web. A vantagem oferecida como estímulo para as empresas participarem está no reconhecimento social de responsabilidade e proteção; além disso, as empresas também recebem acesso a ferramentas de prevenção da exploração sexual (Capital Humano y Social Alternativo, 2018). São requisitos para se tornar membro do The Code:

1. Establecer una política corporativa y procedimientos en contra la de explotación sexual de niños, niñas y adolescentes.

2. Formar al personal de la e mpresa para la prevención de la ESNNA en el ámbito del turismo y los viajes, y en cómo reportar casos.

3. Incluir una cláusula de rechazo a la explotación sexual de niños, niñas y adolescentes, en los contratos del personal y de sus proveedores.

4. Brindar información a sus socios y agentes locales en los lugares de origen y destino en los que opera.

5. Brindar información sobre la ESNNA a los turistas utilizando diversos medios como catálogos, carteles videos informativos a bordo, páginas web, entre otros.

6. Reportar anualmente sobre el avance en la implementación de los 6 criterios (Capital Humano y Social Alternativo, 2018, p. 3).

A United Nations Children's Fund (UNICEF), criada pela ONU em 1946, promove direitos das crianças e dos adolescentes em 190 países. No Peru, a UNICEF trabalha em parceria com o Ministerio del Interior, desde 2007, para detectar casos de exploração sexual infantil e recuperar as vítimas dessa espécie de violência. A unicef (2011) tem

[...] entregado equipos informáticos y audiovisuales de alta tecnología a la Policía Nacional del Perú, al Ministerio Público y al Poder Judicial, los cuales son útiles para la atención y registro de denuncias, identificación de los casos, recuperación de las víctimas, y, sobre todo, prevención de trata de personas a través de la modalidad de explotación sexual infantil (p. 23).

A atuação da UNICEF tem reconhecimento mundial por suas contribuições na busca da proteção de crianças e adolescentes, assim como a atuação da Save The Children, que é uma organização sem fiz lucrativos, fundada em novembro de 1919, a qual concentra seu trabalho na promoção e na defesa dos direitos da criança, em apoio à criança em situação de risco ou violação de direitos, como também na conscientização pública sobre o assunto. O escritório regional da América Latina está localizado em Lima, no Peru.

\section{A proteção jurídica contra o trabalho infantil no Peru}

A Constituição do Peru, lei suprema do país, resguarda o direito de defesa da pessoa humana, respeito pela sua dignidade, pela vida, sua identidade, integridade, desenvolvimento e bem-estar moral, físico e mental. Em seu artigo $4^{\circ}$, estabelece que "la comunidad y el Estado protegen especialmente al niño, al adolescente, a la madre y al anciano en situación de abandono" (Constitución Política del Perú, 1993). Especifica, ainda, que o trabalho tem atenção prioritária, que nenhuma relação de trabalho pode limitar o exercício dos direitos constitucionalmente previstos ou ignorar ou 
diminuir a dignidade do trabalhador. Ademais, segundo artigo 23, "el trabajo, en sus diversas modalidades, es objeto de atención prioritaria del Estado, el cual protege especialmente a la madre, al menor de edad y al impedido que trabajan" (Constitución Política del Perú, 1993).

O Código Civil, com vigência em novembro de 1984, trata brevemente do trabalho infantil no artigo 457, ao afirmar que "el menor capaz de discernimiento puede ser autorizado por sus padres para dedicarse a un trabajo, ocupación, industria u oficio" (Ministerio de Justicia y Derechos Humanos, 1984).

Em 2 de agosto de 1990, a Convenção Internacional sobre os Direitos das Crianças foi aprovada no país por meio da Resolução Legislativa 25.278; desde então, os compromissos firmados em tal Convenção estão sendo cumpridos.

Importante destacar a presença do Código de los Niños y Adolescentes, o qual foi aprovado pela Lei 27.337, em agosto de 2000, marco referencial na garantia de direitos de crianças e adolescentes peruanos. Em seu artigo $3^{\circ}$, estabelece o direito de meninas, meninos e adolescentes de viver em um ambiente saudável e ecologicamente equilibrado. Entende-se que esse artigo visa a evitar que crianças e adolescentes sejam expostos a ambientes insalubres, muito comuns nas atividades de exploração sexual comercial.

Mediante este Código, en el capítulo de Derechos Económicos, Sociales y Culturales, se reconoce el derecho del adolescente a trabajar, siempre y cuando no exista explotación económica y su actividad laboral no implique riesgo o peligro, afecte su proceso educativo o se a nocivo para su salud o para su desarrollo físico, mental, espiritual, moral o social (Fundamentals e Ministerio de Trabajo y Promoción de Empleo del Perú, 2016, p. 26).

Sobre a exploração sexual comercial, o artigo $4^{\circ}$ afirma que os direitos de integridade moral, psíquica e física, liberdade, desenvolvimento e bem-estar de crianças e adolescentes devem ser assegurados, não podendo submeter essas pessoas a nenhuma situação de tortura, tratamento cruel ou degradante, estabelecendo as "formas extremas que afectan su integridad personal, el trabajo forzado y la explotación económica, así como el reclutamiento forzado, la prostitución, la trata, la venta y el tráfico de niños y adolescentes y todas las demás formas de explotación" (Constitución Política del Perú, 1993).

Além das garantias e da proteção aos direitos fundamentais, o código trata da idade mínima para o trabalho, que é de 15 anos para agricultura não industrial; de 16 anos para o trabalho industrial, comercial ou mineira; de 17 anos para a pesca industrial. Em outras modalidades de trabalho, a idade mínima é de 14 anos de idade, podendo, ainda, haver exceções com permissão para o trabalho a partir dos 12 anos de idade, desde que não seja prejudicial à saúde e ao desenvolvimento, nem poderá interferir ou limitar a sua frequência escolar, permitindo sua participação em programas de orientação ou de formação profissional (Fundamentals e Ministerio de Trabajo y Promoción del Empleo del Perú, 2016).

Observa-se que a legislação peruana ainda adota a concepção de proibição do trabalho infantil por setores de atividades econômicas, isto é, a proibição ou regulamentação da idade mínima ocorre de acordo com o tipo de trabalho, que era o modelo da OIT até 1973. Com a adoção da Convenção 138, a OIT reconhece a necessidade de estabelecer limites gerais de idade mínima para o trabalho, pois a cobertura setorial acaba por estimular o uso do trabalho infantil, em especial nas áreas desprotegidas pela lei. Assim, a idade mínima estabelecida pelo Código de los Niños y Adolescentes, do Peru, viola o atual entendimento da OIT, de acordo com a Convenção $138^{2}$.

2 "Artigo 2 - 1. Todo Membro, que ratifique a presente Convenção, deverá especificar, em uma declaração anexa à sua ratificação, a idade mínima de admissão ao emprego ou ao trabalho em seu território e nos meios de transporte registrados em seu território; à exceção do disposto nos artigos 4 e 8 da presente Convenção, nenhuma pessoa com idade menor à idade declarada, deverá ser admitida ao emprego ou trabalhar em qualquer ocupação. 2. Todo Membro, que tenha ratificado a presente Convenção, poderá notificar, posteriormente, o Diretor Geral do Secretariado da Organização Internacional do Trabalho, mediante outra declaração, que estabeleça uma idade mínima mais alta que a que determinou inicialmente. 3. A idade mínima fixada em cumpri- 
Outro salto normativo na busca pela efetivação dos direitos de crianças e adolescentes, ao que se refere ao trabalho infantil, tem-se na Lei 28.806 , de julho de 2006, a "Ley General de Inspección del Trabajo" (Fundamentals e Ministerio de Trabajo y Promoción del Empleo del Perú, 2016, p. 28), que promove a fiscalização, o monitoramento e a exigência de cumprimento de normas regulamentadoras das condições de trabalho, condições contratuais, regime de trabalho infantil, para que não ocorra violações das disposições normativas e, também, a fim de promover segurança e saúde no trabalho infantil.

Por meio do Decreto Supremo 003-2010MIMDES $^{3}$, de abril de 2010, o qual aprova a "Relación de trabajos peligrosos y actividades peligrosas o nocivas para la salud integral y la moral de las y los adolescentes" (Fundamentals e Ministerio de Trabajo y Promoción del Empleo del Perú, 2016, p. 28), estão estabelecidas quais são as atividades perigosas ou nocivas à saúde, bem como a idade mínima permitida para o trabalho de adolescentes nas respectivas atividades perigosas.

mento do disposto no parágrafo 1 do presente artigo, não deverá ser inferior à idade em que cessa a obrigação escolar, ou em todo caso, a quinze anos. 4. Não obstante os dispositivos do parágrafo 3 deste artigo, o Membro cuja economia e sistemas educacionais não estejam suficientemente desenvolvidos poderá, mediante prévia consulta às organizações de empregadores e de trabalhadores interessadas, se tais organizações existirem, especificar, inicialmente, uma idade mínima de quatorze anos. 5. Todo Membro, que tenha especificado uma idade mínima de quatorze anos, conforme o disposto no parágrafo precedente, deverá declarar, nos relatórios que se comprometeu a apresentar por força do artigo $22 \mathrm{da}$ Constituição da Organização Internacional do Trabalho: a) que subsistem os motivos para tal especificação, ou b) que renuncia ao direito de continuar amparando-se no parágrafo acima, a partir de uma determinada data” (Organização Internacional do Trabalho, 1973).

3 Trata-se de decreto emitido pelo Ministerio de la Mujer y Desarrollo Social (MIMDES).
O Decreto Supremo 015-2012-TR ${ }^{4}$, de setembro de 2012, que aprovou a "Estrategia nacional para la prevención y erradicación del trabajo infantil (ENPETI)" (Fundamentals e Ministerio de Trabajo y Promoción del Empleo del Perú, 2016, p. 28), com metas de 2012 a 2021, para prevenção e erradicação do trabalho infantil, trouxe políticas públicas nacionais, especialmente para combate das piores formas de trabalho infantil e exploração de crianças e adolescentes. O ENPETi é uma estratégia do Estado para proteger crianças e adolescentes em todos os setores, com a participação de instituições públicas e privadas, levando em consideração os princípios do trabalho decente $\mathrm{e}$ de uma educação de qualidade, além da prevenção e da erradicação do trabalho infantil.

Por meio do decreto é possível perceber não só a responsabilidade imposta ao Estado, em prevenir e erradicar o trabalho infantil, mas ambém a responsabilidade compartilhada, que incentiva os atores privados, a sociedade, a comunidade e a família na busca para erradicação do trabalho infantil. O ENPETI está estruturado em seis grandes eixos estratégicos para atingir seus objetivos:

Eje 1: Pobreza. Objetivo específico 1: Incrementar el ingreso promedio de las famílias pobres, com niños en riesgo, o en trabajo infantil, de modo sostenible.

Eje 2: Educación y uso del tiempo libre. Objetivo específico 2: Incrementar la conclusión oportuna de la educación básica y el uso creativo del tiempo libre de los niños.

Eje 3: Tolerancia Social. Objetivo específico 3: Reducir la tolerancia social al trabajo infantil

Eje 4: Condiciones de trabajo. Objetivo específico 4: Mejorar las condiciones laborales del trabajo adolescente permitido.

Eje 5: Protección. Objetivo específico 5: Incrementar y fortalecer servicios de detección, protección y sanción frente al trabajo infantil peligroso y a la explotación infantil y adolescente.

Eje 6: Información y conocimiento (eje transversal). Objetivo específico 6: Identificar el trabajo

4 Decreto emitido pelo presidente da república peruana, para fins de regulamentação de normas trabalhistas. 
infantil y generar información y conocimiento (Fundamentals e Ministerio de Trabajo y Promoción del Empleo del Perú, 2016, pp. 29-30).

Outro importante avanço normativo é o Decreto Supremo 011-2014-TR, chamado Protocolo Interserctorial contra el Trabajo Forzoso, promulgado em outubro de 2014, que trata sobre o trabalho forçado e a importância do trabalho entre diferentes setores em cinco fases para rota de ação: 1) a promoção de informações sobre o trabalho forçado; 2) a prevenção; 3) a detecção de empresas e empregadores que exploram o trabalho infantil; 4) a identificação de vítimas do trabalho forçado e 5) a sua recuperação (Fundamentals e Ministerio de Trabajo y Promoción del Empleo del Perú, 2016, p. 30).

Além desse decreto, há a Lei 30.362, promulgada em outubro de 2015, a qual declara o interesse nacional e a atenção preferencial na alocação de recursos públicos para garantir o PNAIA 2012-2021. O plano busca a ação do Estado e da sociedade civil para o desenvolvimento integral das crianças peruanas a fim de erradicar o trabalho infantil entre o período de 2012 e 2021. Nos parâmetros constitucionais e de acordo com a Convenção sobre Direitos das Crianças, bem como seus protocolos facultativos, elenca quatro principais objetivos, dos quais três estão diretamente ligados ao trabalho infantil: garantia ao crescimento e desenvolvimento integral de crianças de 0 a 5 anos de idade; proteção ao trabalho infantil para crianças de 6 a 11 anos de idade; proteção ao trabalho perigoso aos adolescentes de 12 a 17 anos de idade; proteção a todas crianças e adolescentes às situações de tráfico (sexual, laboral, mendicância).

O plano afirma que o trabalho infantil é um fator de risco à sociedade, pois tem como consequência a continuidade da baixa renda e a evasão escolar. Apesar da proibição, crianças continuam trabalhando em razão da estreita relação de pobreza e da forte cultura de trabalho infantil que deve ser combatida (Fundamentals e Ministerio de Trabajo y Promoción del Empleo del Perú, 2016, p. 28).

a) O programa "El Estado y la Sociedad Civil contra el Abuso y la Explotación Sexual de Niños, Niñas y Adolescentes" busca fortalecer o sistema público do país para intervir nos casos de violência, abuso e exploração sexual de crianças e adoles- centes por meio de ações estratégias: Promoción y prevención, como una forma de generar cambios en los modelos de crianza para estimular un adecuado desarrollo socioemocional de niños, niñas y adolescentes, reconociéndoles como personas con derechos, trabajando con madres, padres y maestros de escuela, proporcionándoles información y promoviendo habilidades y destrezas que faciliten cambios de conducta, percepciones y actitudes.

b) Atención y protección de víctimas mediante un sistema de detección, denuncia oportuna y respuesta eficaz frente a los casos, para interrumpir la cadena intergeneracional de la violencia.

c) Recuperación y reinserción social de las niñas, niños y adolescentes víctimas, mediante el fortalecimiento y mejora de la respuesta de los servicios públicos.

d) Adecuación de las políticas públicas y participación de las comunidades para desarrollar e implementar mecanismos de vigilancia y apoyo social contra las prácticas de violencia, abuso sexual infantil y explotación sexual infantil (Martín e Ponce, 2008, p. 12). [cita]

O programa El Estado y la Sociedad Civil contra el Abuso y la Explotación Sexual de Niños, Niñas y Adolescentes pertence ao Ministerio de la Mujer y Desarrollo Social, ministério que tem o apoio da UNICEF. Contudo, essas políticas públicas e normas jurídicas estão em consonância com as causas que levam a exploração sexual comercial no turismo?

\section{Exploração sexual comercial de crianças e adolescentes no turismo}

A exploração sexual comercial de crianças e adolescentes é uma espécie de trabalho infantil e um problema de saúde pública em todos os países. Trata-se de um tema de relevância, pois ainda que haja normas jurídicas que assegurem os direitos de crianças e adolescentes e mesmo havendo atuação de políticas públicas que visam à prevenção e à erradicação dessa forma de violência, a quantidade de casos denunciados às autoridades é significativa, ainda que nem todos os casos sejam denunciados. 
Entre os esforços do governo, das organizações não governamentais e da sociedade civil no combate à exploração sexual comercial de crianças e adolescentes, visando à garantia de direitos fundamentais, tem-se o importante trabalho da ECPAT. Um dos principais estudos da ECPAT diz respeito ao Sexual Exploitation of Children in Travel and Tourism (SECTT) ${ }^{5}$, que é a exploração sexual de crianças em viagens e turismo. Apesar de o turismo e as viagens serem uma importante atividade econômica global em razão dos empregos que geram direta e indiretamente em hotéis, transporte, construção, comércio, alimentação, além de afetar a cultura e as normas sociais de comunidades que entram em contato com o turismo, propiciam também a exploração sexual infantil (ECPAT, 2016).

O fluxo maciço de turistas e viajantes traz consigo dinheiro e oportunidades de trabalho, especialmente quando se tem como destino locais com alto nível de pobreza e desigualdade social. Além dos estudos que reconhecem os benefícios econômicos da indústria de viagens e turismo, é preciso olhar também para a alta dependência financeira dessas famílias, criando uma condição propícia para que crianças e adolescentes sejam sexualmente explorados por pessoas em trânsito (ECPAT, 2016).

Essa foi uma das discussões na reunião da Rede Mundial de Turismo em Proteção à Criança, ocorrida em Berlim, em março de 2015, em que uma das pautas foi o ligeiro aumento de turismo no mundo em razão de diversos fatores, como melhorias nas condições de salário, direitos a férias, grandes promoções e parcelamentos de agências de viagens e empresas de viação, globalização da informação, principalmente pela internet. Esses fatores, que alavancaram o turismo, melhoraram a economia dos lugares turísticos, mas, consequentemente, aumentaram a exploração sexual comercial infantil.

Over time the phenomenon of domestic and international travelling child sex offenders, coming Offenders are increasingly adept at using the travel and tourism industries as a route to child exploitation; and the Internet has heightened the

5 É a forma como a End Child Prostitution, Child Pornography and Trafficking of Children for Sexual Purposes (ECPAT) nomeia as situações de exploração sexual de crianças em viagens e turismo. dangers for children as child sex offenders can contact children directly and anonymously. Destinations evolve quickly and frequently, as a result of the from various backgrounds, has evolved. development of new tourism destinations but also economic, social and political developments. As soon as prevention and protection efforts are intensified in a particular country, child sexual exploiters seem to move on to another country (UNwTo, 2015, p.02).

A globalização econômica tem causado aumento da violência. As novas formas de comunicação e a pobreza são fenômenos que dão força para aqueles que buscam impunidade a distância para cometer crimes ou para negociar sexo com crianças e adolescentes, como se fosse uma atividade recreativa fornecida pelo local (Terrero, 2014, p. 12).

Pesquisas realizadas nessa área apontam para a exclusão socioeconômica e a pobreza como os dois dos grandes responsáveis pelas relações sexuais comerciais infantis. Segundo dados trazidos pela ECPAT $(2016$, p. 16), a população no Peru é de 30.375 .603 pessoas, em que 10.480 .025 são crianças e adolescentes com idades até 18 anos, representando, assim $34,5 \%$ da população. Entre o número de crianças e adolescentes peruanas, 62,6\% vivem em situação de pobreza e 30,9\% vivem em situação de extrema pobreza.

Segundo dados apresentados pelos pesquisadores Martín Benavides e Carmen Ponce, do Grupo de Análisis para el Desarrollo (GRADE), em coordenação com a UNICEF, $45 \%$ da população encontra-se em situação de pobreza e $16 \%$ em extrema pobreza. Dessa estatística, o grupo mais afetado pela pobreza e extrema pobreza no Peru são de crianças e adolescentes:

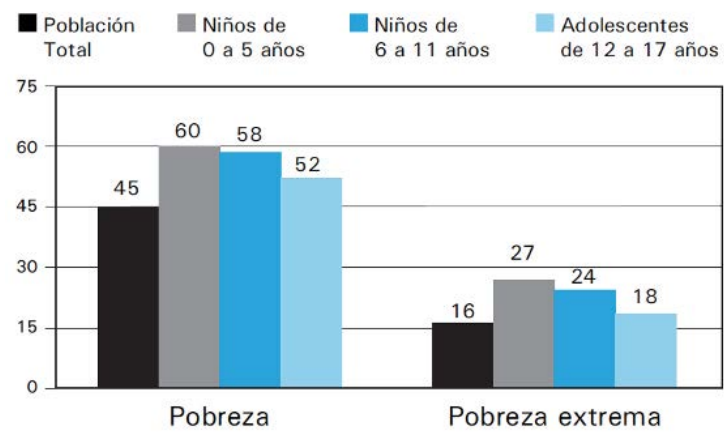

Gráfico 1. Pobreza e pobreza extrema na infância e na adolescência em porcentagem

Fonte: Martín, B. e Ponce, C. (2008). 
O gráfico demonstra que a maior concentração de pobreza ou de extrema pobreza atinge crianças de zero a cinco anos de idade, seguido por crianças de seis anos e onze anos de idade, Martín e Ponce explicam:

En la población total la tasa de pobreza es de $45 \%$, cifra que en el grupo de niños y niñas de 0 a 5 años aumenta a $60 \%$ y en el de 6 a 11 años a 58\%, siendo más de 10 puntos porcentuales mayor que la tasa de pobreza en la población total. En el caso de la pobreza extrema la situación es también crítica. Entre los niños y niñas de 0 a 5 años ésta alcanza al $27 \%$ y entre los de 6 a 11 años al 24\%, alrededor de 10 puntos porcentuales mayor que la tasa de pobreza extrema en la población total (16\%) (Martín e Ponce, 2008, p. 12).

Referente ao trabalho infantil de modo geral, isto é, sem a verificação específica da espécie de trabalho aqui estudada, o levantamento realizado pelo grupo de pesquisas GRADE diagnosticou que, em 2006, em todo território peruano, cerca de $20 \%$ das crianças, entre 6 e 11 anos, tiveram algum trabalho, e que $40 \%$ dessas crianças trabalharam no meio rural (Martín e Ponce, 2008, p. 76).

Ainda que a Convenção sobre os Direitos das Crianças tenha estabelecido que crianças e adolescentes têm direito de serem protegidos da exploração econômica e de qualquer forma de trabalho que possa ser perigoso ou que possa atrapalhar o desenvolvimento educacional, a saúde, o estado físico, psíquico, mental, espiritual, moral e social, os índices de trabalho são elevados.

La Convención sobre los Derechos del Niño establece que el niño tiene derecho a estar protegido contra la explotación económica y contra el desempeño de cualquier trabajo que pueda ser peligroso o entorpecer su educación. Asimismo, tiene derecho a estar protegido contra cualquier trabajo que sea nocivo para su salud o su desarrollo físico, mental, espiritual, moral o social. Como complemento, el Perú aprobó en el año 2001 el convenio 182 de la Organización Internacional del Trabajo (OIT), que prohíbe las peores formas de trabajo infantil y adolescente, y en conformidad con el convenio 138 de la OIT se establece los 14 años como edad mínima para empezar a trabajar. Con el fin de asegurar el cumplimiento progresivo de la normatividade que prohíbe el trabajo infantil y regula el trabajo adolescente, en el año 2003 se creó el Comité Directivo Nacional para la Prevención y Erradicación del Trabajo Infantil. (Martín e Ponce, 2008, p. 76).

Apesar das iniciativas nacionais e internacionais de combate ao trabalho infantil no mundo e no Peru, a participação de crianças e adolescentes em atividades nocivas ao seu desenvolvimento colocam em risco sua saúde e educação. Outro fator que aumenta a SECTT é a alta evasão escolar, grande parte decorrente da exploração do trabalho infantil. Em famílias que não podem garantir as necessidades básicas de seus membros, as demandas de trabalho e os meios de subsistência são frequentemente transferidos para as crianças (ECPAT, 2016, p. 28).

De acordo com os dados apresentados pelo grupo de pesquisas GRADE a maior concentração de trabalho infantil está nas áreas rurais, atingindo $40 \%$ das crianças, seguido pela selva, onde são quase $15 \%$ de meninos e meninas que trabalham em horário escolar. "Jornadas muy intensas parecen ser incompatibles con la asistencia a la escuela y el aprendizaje” (Martín e Ponce, 2008, p. 76).

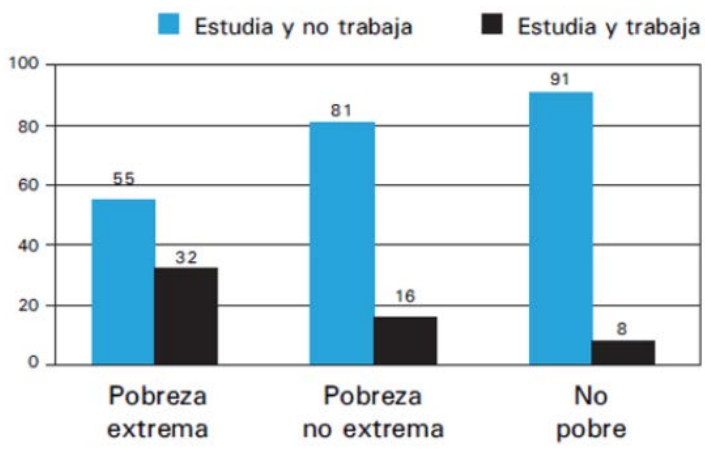

Gráfico 2. Crianças trabalhadoras de acordo com a condição de pobreza em porcentagem.

Fonte: Martín, B. e Ponce, C. (2008).

Existe um consenso indireto sobre as informações a respeito da exploração sexual comercial no turismo, que se manifesta principalmente pela falta de dados e mecanismos para reunir, analisar e monitorar o número de casos de SECTT. Um dos temas abordados pelo levantamento do grupo de pesquisa GRADE trata da exploração 
sexual em razão da importância da problemática, que afeta principalmente as adolescentes. Todavia, no próprio documento gerado pelo GRADE, menciona-se que "no fue posible presentar un diagnóstico del tema debido a la limitada información disponible" (Martín e Ponce, 2008, p. 96), justamente pela dificuldade de se ter acesso a informações relativas à exploração sexual comercial de crianças e adolescentes.

Ainda que a legislação peruana permita o trabalho de adolescentes a partir dos 14 anos e, em alguns casos, a partir dos 12 anos de idade, a OIT proíbe atividades que coloquem em risco sua saúde física ou moral. Contudo, existe um problema gravíssimo de exploração comercial de crianças e adolescentes, apesar de ser crime na lei peruana, pois é uma violação do direito à saúde moral e física.

Apesar de existir legislação geral sobre trabalho infantil no Peru, o tema específico da exploração sexual comercial infantil no turismo também é tratado brevemente no:

- The National Action Plan for Childhood and Adolescence 2012-2021 recognises CSE as an issue and explicitly mentions SECTT (Expected result 14, literal b): "Commit tourist operators to working towards the eradication of focal points for child sexual exploitation.” This involves the Ministry of Foreign Trade and Tourism (MINCETUR).

- Minceturdesigned the "Guide for Tourism Service Providers: From Onlookers to Actors" to prevent sectr, the "Stop Child Sex Tourism" campaign, and encouraged legal changes such as Supreme Decree N. 007-2007-MINCETUR that criminalises the infractions of tourism service providers that promote and permit CSE in their establishments.

- Peru also has the National Action Plan Against human trafficking in Peru 2011-2016, which recognises SECTT as a mode of SEC in human trafficking, however, in the intervention matrix in the National Plan, there are no actions to support the work in this issue (ЕСРAT, 2016, p. 95).

Poucos avanços estão relacionados com esse tema. Apesar da vasta legislação nacional e internacional para resguardar crianças e adolescentes de trabalhos perigosos e insalubres, pouco se fala na exploração comercial sexual de crianças e adolescentes no turismo. A Lei 2.8251, de 2004, que modifica e incorpora artigos referentes a violência sexual, exploração sexual comercial e pornografia infantil no atual Código Penal do Peru, reconhece a exploração sexual comercial de crianças no contexto de viagens e turismo, todavia somente no caráter punitivo, segundo o artigo 181-A, que diz:

El que promueve, publicita, favorece o facilita el turismo sexual, a través de cualquier medio escrito, folleto, impreso, visual, audible, electrónico, magnético o a través de internet, con el objeto de ofrecer relaciones sexuales de carácter comercial de personas de catorce y menos de dieciocho años de edad será reprimido con pena privativa de libertad no menor de dos ni mayor de seis años (Ministerio de Justicia y Derechos Humanos, 1991).

Outra medida adotada pelo Peru que representa um efetivo avanço é a Lei de Turismo 29.408 , de 2009. A partir dela passou-se a regular atividades administrativas dos prestadores de serviços, colocando-os também como responsáveis pela prevenção de SECTT, contribuindo por meio da divulgação de leis contra a exploração sexual comercial de crianças. Também atribuiu ao Ministério do Comércio Exterior e do Turismo a tarefa de monitorar e emitir as leis necessárias para prevenir e combater o SECTT, a fim de garantir a dignidade física, moral e psíquica das crianças e adolescentes peruanas.

\section{A mercantilização de pessoas: uma sociedade que não vive, sobrevive}

Os índices de trabalho infantil e de exploração sexual comercial demonstram consideráveis incidências das piores formas de violação aos direitos humanos, fundamentais para crianças e adolescentes. "A exploração sexual comercial como fenômeno complexo e multifacetário, presente na sociedade contemporânea, está intrinsecamente ligada às várias formas de organização econômico-capitalista e no contexto de uma realidade social profundamente excludente e injusta" (Custódio e Moreira, 2015, p. 21). Há um número imenso de pessoas em todo o mundo que são vítimas de várias formas de privação de 
liberdade, assim, impossibilitadas de desenvolvimento humano e social. Segundo Sen (2000),

A privação de liberdade pode surgir em razão de processos inadequados (como a violação do direito ao voto ou de outros direitos políticos civis), ou de oportunidades inadequadas que algumas pessoas têm para realizar o mínimo do que gostariam (incluindo a ausência de oportunidades elementares como a capacidade de escapar de morte prematura, morbidez evitável ou fome involuntária) (p. 31).

A liberdade é um fator fundamental para o desenvolvimento da sociedade. Crianças e adolescentes que são sexualmente explorados, de forma comercial, encontram-se privados de sua liberdade, de desenvolver-se como seres humanos instituídos de direitos, e são atingidos pelos piores reflexos da exploração capitalista e globalizada: a perda de dignidade sexual.

Ademais, faz-se necessário a remoção das principais fontes de privação de liberdade, entre elas "pobreza e tirania, carência de oportunidades econômicas e destituição social sistemática, negligência dos serviços públicos e intolerância ou interferência excessiva de Estados repressivos" (Sen, 2000).

As piores formas de violação dos direitos no trabalho infantil advêm da escravidão forçada, em que crianças de famílias desfavorecidas são forçadas a um emprego que as explora, tira sua liberdade e dignidade (Sen, 2000). A mercantilização de pessoas é decorrente do atual modelo de globalização, uma vez que grande parte da humanidade está à mercê de uma fábrica de perversidades. Com o desemprego crescente, a pobreza aumenta e as classes médias perdem em qualidade de vida, o salário médio tende a baixar, novas enfermidades surgem, a mortalidade infantil permanece. Mesmo com o progresso da medicina e da informação, a educação de qualidade é cada vez mais inacessível (Santos, 2002).

A exploração sexual comercial infantil é uma relação de mercantilização: envolve exploração, dominação, abuso de poder do corpo de crianças e de adolescentes. Além da oferta por exploradores sexuais, que agem como comerciantes, a comercialização pode estar organizada em redes de marketing locais ou globais. Nesse viés, considerando a lógica da globalização do mercado, a crise do trabalho e dos valores sociais, quem sofre diretamente essa crise são as pessoas que se encontram em situação de pobreza ou extrema pobreza, entre elas as crianças e os adolescentes. Na quebra de contratos sociais e direitos humanos, a sociedade é compelida a conviver experiências de sobrevivência que recriam formas antigas de precariedade de direitos e de trabalho no capitalismo.

Essa flexibilização, resultante de uma mudança estrutural dos valores, reflete nas relações familiares, no abandono dos valores familiares, escolares e sociais. Crianças e adolescentes acabam se tornando alvos fáceis no mercado da exploração sexual comercial no turismo. Recrutados e atraídos por exploradores, enganados por falsas promessas de valores, alimentos, artigos de consumo, concordam em se submeter a uma ordem de trabalho perversa, induzidos por questões de necessidade material e econômica e pela lógica consumista da sociedade capitalista (Leal, 2003).

Es de la naturaleza del mercado construir estrategias que hacen disponibles al consumidor, a través del comercio, una variedad de productos y bienes de consumo, elaborados por la fuerza del trabajo humano (sea asalariada/explotada o esclavizada) y por el reclutamiento forzado del trabajo infantil. El mercado hace disponible también la venta de prestación de servicios, incluso los sexuales, y se expande y se diversifica de acuerdo a las transformaciones del capital (p. 9).

Segundo Leal, "Globalizar los derechos y el desarrollo social de niños, niñas y adolescentes es el fundamento ético del enfrentamiento contra la explotación sexual comercial de niños, niñas y adolescentes en los niveles nacional e internacional" (Leal, 2003, p. 10). A pobreza estrutural globalizada alcançou uma espécie de naturalização, que "seria politicamente produzida pelos atores globais com a colaboração consciente dos governos nacionais e, contrariamente às situações precedentes, com a conivência de intelectuais contratados - ou apenas contatados - para legitimar essa naturalização" (Santos, 2002). Nas condições atuais, sai-se de uma pobreza para entrar em outra, deixa-se de ser pobre em um lugar 
para ser pobre em outro; esse é o atual modelo de globalização, que influencia uma universalidade de países, levando às consequências extremas, como da mercantilização de pessoas.

A globalização em nada contribui para a efetivação de direitos humanos, na verdade ela apenas coloca os interesses econômicos à frente dos seres humanos e de seus direitos. Para uma outra globalização é necessária "uma mudança radical das condições atuais, de modo que a centralidade de todas as ações seja localizada no homem. Sem d úvida, essa desejada mudança apenas ocorrerá no fim do processo, durante o qual reajustamentos sucessivos se imporão" (Santos, 2002).

Uma possível mudança nos modelos atuais começaria por atitudes mais solidárias, de proteção e compaixão nas relações interpessoais. Deveria haver uma preocupação maior com a condição de humanidade da maior parte da população do mundo e a diminuição da importância da economia global, com consequente valoração de todos. Contudo, a economia global apenas "tem trazido como consequência para todos os países uma baixa de qualidade de vida para a maioria da população e a ampliação do número de pobres em todos os continentes" (Santos, 2002).

O que se verifica atualmente é um aumento descontrolado dos interesses econômicos, tanto do Estado como das instituições privadas e da própria sociedade dominada pelo hiperconsumismo e pelo egoísmo. Esse comportamento gera graves violações aos direitos humanos em âmbito mundial evidenciado pela exploração econômica das liberdades pessoais de adultos, de crianças e de adolescentes, aumentando a ausência de qualidade de vida, a exclusão e a discriminação.

Para o enfrentamento da globalização e da mercantilização dos próprios corpos para sobreviver ao Estado capitalista, como ocorre em problemas como exploração sexual comercial de crianças e adolescentes, é de suma importância o desenvolvimento de políticas públicas de garantia de direitos para o enfrentamento de tal problema de forma específica. Os compromissos internacionais e nacionais são grandes aliados para formulação de estratégias que visam aos direitos humanos, principalmente de crianças e adolescentes, pessoas em situação de desenvolvimento e que necessitam de um olhar atento do Estado, da sociedade e da família para garantir proteção e condições necessárias para seu crescimento saudável.

\section{Conclusão}

A exploração sexual comercial de crianças e adolescentes não pode ser vista apenas como um ato criminoso, mas também como uma questão social. Assim, devemos desmitificar que as questões que levam a essa violação de direitos é por opção ou consentimento, visto que a causa advém de questões moralistas e repressivas.

O fenômeno é conhecido por todos, e encontra aceitação pela sociedade em sua omissão, mas ao mesmo tempo não é visível no debate público e institucional, está sujeito somente à esfera íntima da família ou do mercado. A sexualidade da criança e do adolescente não é concebida como um direito, negando que essas pessoas sejam sujeitos de direito.

$\mathrm{O}$ poder aquisitivo dos viajantes e turistas torna-se atrativo para sociedades que vivem em situação de pobreza e extrema pobreza. O trabalho infantil é a tentativa de acesso ao consumo básico, como a comida. A consequência disso é devastadora para as crianças, pois cria uma cultura de normalização para a exploração sexual comercial infantil, tornando-se uma atividade atrativa para turistas.

Ainda que diante da regulamentação para proteção, prevenção e punibilidade aos sujeitos que violam os direitos de crianças e adolescentes quanto ao trabalho infantil e dignidade sexual, as crianças ainda estão expostas à violação de direitos humanos. As consequências são devastadoras para a sociedade como um todo, pois a violação de direitos da criança e do adolescente pela exploração sexual comercial infantil liga o turismo à violação de direitos, que tem sua imagem gravemente danificada, torna os locais mais perigosos e o movimento sustentável reduz. A pobreza, combinada com a negligência contínua dos sistemas de proteção infantil, tem contribuído para a comercialização de crianças. Pouco se sabe sobre o comportamento dos 
turistas, e há pouca preocupação sobre o controle de suas ações, nem há a preocupação de atendimento às condições mínimas e aos direitos fundamentais básicos para desenvolvimento saudável dessas crianças e desses adolescentes.

$\mathrm{Na}$ América Latina, uma vasta gama de estratégias preventivas tem se desenvolvido especificamente no contexto de viagens e turismo, principalmente por ONGs em parceria com órgãos do governo responsáveis pela indústria do turismo e com colaboração do setor de turismo e organizações internacionais. As estratégias incluem campanhas, materiais informativos e iniciativas comunitárias focados no treinamento e na capacitação de líderes comunitários, crianças e jovens e aqueles ligados ao trabalho formal e indústrias turísticas informais para ajudá-los a evitar a exploração sexual de crianças e adolescentes no turismo, protegendo-os de toda forma de violência, abuso e exploração. A legislação nacional e os planos trabalham em perspectivas mais preventivas e punitivas, sem atacar as verdadeiras causas da exploração sexual comercial no turismo, a globalização e a pobreza.

As ONGs, os conselhos de direitos, os centros de defesa, os fóruns e os movimentos de crianças e adolescentes têm papel estratégico de mobilizar forças políticas nacionais e internacionais para desconstruir a violência sexual comercial e reinventar outra globalização pautada na defesa dos direitos e no desenvolvimento de sujeitos em situação de vulnerabilidade social.

Contudo não é só isso que basta, faz-se necessária a atuação estatal na garantia de direitos fundamentais básicos, que assegurem a proteção social das famílias expostas à situação de pobreza e extrema pobreza, apresentando meios alternativos para sobreviverem à globalização. Além disso, existe o grande desafio de fortalecer as articulações das redes de confronto, de mobilizar todos os setores públicos e privados para enfrentar o fenômeno.

\section{Referências}

Brasil (1990). Decreto 99.710 de 21 de novembro de 1990 que promulga a Convenção sobre os Direitos da Criança. Brasília: Casa Civil. Recuperado de http://www.planalto.gov.br/ccivil_03/decreto/1990-1994/d99710.htm
Capital Humano y Social Alternativo (2018). Por un turismo seguro para los niños, niñas y adolescentes. Recuperado de http://chsalternativo.org/recurso/ the-code-por-un-turismo-responsable-para-ninas-ninos-y-adolescentes/

Constitución Política del Perú (1993). Ley 27.337 del 7 de agosto de 2000 por la cual se promulgó el código de los niños y adolescentes. Recuperado de http://www.sipi. siteal.iipe.unesco.org/derechos/453/derecho-la-educacion

Constitución Política del Perú (1993). Lima: Congreso de la República del Perú. Recuperado de http://www2. congreso.gob.pe/sicr/RelatAgenda/constitucion. nsf $/ \$$ ViewTemplate $\% 20$ for $\% 20$ constitucion? OpenForm \&Start $=1 \&$ Count $=30 \&$ Expand $=1 \&$ Seq $=1$

Costa, M. M. M. da e Veronese, J. R. P. (2006). Violência doméstica: Quando a vítima é criança ou adolescente. Florianópolis: $\mathrm{OAB} / \mathrm{sC}$.

Custódio, A. V. e Moreira, R. B. da R. (2015). Exploração sexual comercial de crianças e adolescentes: Reflexões contemporâneas no contexto do Brasil, da Argentina e do Uruguai. Curitiba: Multideia.

Custódio, A. V. e Veronese, J. R. P. (2007). Trabalho infantil: A negação do ser criança e adolescente no Brasil. Santa Catarina: OAB/sC.

Custódio, A. V. e Veronese, J. R. P. (2013). Trabalho infantil doméstico. São Paulo: Saraiva.

End Child Prostitution and Trafficking. (2016). Global study on sexual eploitation of children in travel and tourism: Regional report Latin America. Tailândia: ECPAT. Recuperado de http://www.ecpat.org/about-ecpat

Fundamentals y Ministerio de Trabajo y Promoción del Empleo del Perú (2016). Magnitud y características del trabajo infantil en Perú: Informe de 2015 - Análisis de la Encuesta Nacional de Hogares (EnAHo) y de la Encuesta sobre Trabajo Infantil (ETI). Ginebra: OIT. Recuperado de http://www.ilo.org/lima/publicaciones/ WCMS_534921/lang--es/index.htm

Leal, M. L. P (2003). Globalización y explotación sexual comercial de niños, niñas y adolescentes. Lima: Save the Children. Recuperado de https://resourcecentre.save thechildren.net/sites/default/files/documents/1322_0.pdf

Martín, B. e Ponce, C. (2008). Estado de la niñez en el Perú. Lima: UNICEF.

Ministerio de Justicia y Derechos Humanos (1984). Decreto legislativo 295 del 25 de julio de 1984 mediante el cual se promulgó el Código Civil. Recuperado de http://spij.minjus.gob.pe/notificacion/guias/ CODIGO-CIVIL.pdf

Ministerio de Justicia y Derechos Humanos (1991). Decreto legislativo 635 del 3 de abril de 1991 mediante el cual se promulgó el Código Penal. 
Recuperadodehttp://bcn.gob.ar/uploads/Dossier-N-34--actualizacion-2017---Regimen-Penal-de-Menores.pdf

Mujica, J. N. (2013). El trabajo infantil en el ordenamiento internacional y peruano. Boletín Ministerio de Trabajo Y Promoción del Empleo. Recuperado de http://www. trabajo.gob.pe/boletin/boletin_28.html

Organização Internacional do Trabalho (1973). Convenção 138 sobre a idade mínima de admissão ao emprego. Recuperado de http://www. tst.jus.br/documents/2237892/0/Conven\%C3\%A $7 \% \mathrm{C} 3 \% \mathrm{~A} 3 \mathrm{o}+138+\mathrm{da}+\mathrm{OIT}++\mathrm{Id}$ ade $+\mathrm{m} \% \mathrm{C} 3 \% \mathrm{~A}$ Dnima+de+admiss\%C3\%A3o+ao+emprego

Organização Internacional do Trabalho (1999). Convenio sobre la prohibición de las peores formas de trabajo infantil y la aación inmediata para su eliminación. Recuperado de http://www.ilo.org/public/spanish/ standards/relm/ilc/ilc87/com-chic.htm

Organização Internacional do Trabalho (1999). Recomendação 190 sobre a proibição daspiores formas de trabalho infantil e ação imediata para sua eliminação. Recuperado de http://www.tst.jus.br/documents/2237892/0/ Recomenda\%C3\%A7\%C3\%A3o+190+da+OIT+ sobre+Proibi\%C3\%A7\%C3\%A3o+e+a\%C3\%A7\% C $3 \%$ A $30+$ imediata + para $+a+$ elimina $\%$ C $3 \%$ A 7 $\% \mathrm{C} 3 \% \mathrm{~A} 3 \mathrm{o}+$ das+piores+formas+de+trabalho+infantil

Santos, M. (2002). Por uma outra globalização. 6. ed. Rio de Janeiro: Record.

Sen, A. (2000) Desenvolvimento como liberdade. São Paulo: Companhia das Letras.

Terrero, L. S. (2014). Social impacts of tourism in Brazil. Global Sustainable Tourism Review, 2014. Recuperado de http:/qualitycoast.info/wp content/uploads/2014/03/ Dossier-Brazil-Social-impacts.pdf

UniCeF (2011). Informe Perú 2011. Recuperado de http://repositorio.minedu.gob.pe/bitstream/ handle/123456789/675/386.\%20Estado\%20de $\% 20$ la\%20ni\%C3\%B1ez\%20en\%20 el\%20Per\%C3\%BA.. pdf?sequence $=1$

UNWTO (2015). Report of the 30th meeting of the world tourism network on child protection (formerly the Task Force for the Protection of Children in Tourism). Recuperado de https://webunwto.s3-euwest-1.amazonaws.com/imported_images/42802/ rev30thmeeting reportof heworld tourism net workonchildprotection revnm.pdf?fbclid=IwAR 2qTeG9DvGgb8XUtNi-zlWeeoELWnwFUU8ceb DL8X8HMv1NSBdWf2mGJPQ

Veronese, J. R. P. (2013). A proteção integral da criança e do adolescente no direito brasileiro. Revista TST, 76(1). Recuperado de https://aplicacao.tst.jus.br/ dspace/bitstream/handle/1939/38644/003_veronese. pdf? sequence $=1$ 